\title{
Odorant Receptor Sensitivity Modulation in Drosophila
}

\author{
${ }^{\circ}$ Hao Guo, ${ }^{1}$ Kishor Kunwar, ${ }^{1}$ and Dean Smith ${ }^{1,2}$ \\ Departments of ${ }^{1}$ Pharmacology and ${ }^{2}$ Neuroscience, University of Texas Southwestern Medical Center, Dallas, Texas 75390-9111
}

The ability to modulate sensitivity in sensory systems is essential for useful information to be extracted from fluctuating stimuli in a wide range of background conditions. The mechanisms underlying sensitivity regulation in insect primary olfactory neurons are poorly understood. Here we reveal that dephosphorylation of Orco ${ }^{\text {S289 }}$ that occurs upon prolonged odor exposure is a mechanism underlying reduction in odorant sensitivity in Drosophila primary olfactory neurons in both sexes. Orco ${ }^{S 289 \mathrm{~A}}$ mutants, unable to phosphorylate this position, have low intrinsic odorant sensitivity that is independent of altered expression or localization. A phosphomimetic allele, $\operatorname{Orco}^{S 289 D}$, has enhanced odorant sensitivity compared with wild-type controls. To explore the functional ramifications of this phosphorylation in vivo, we generated phospho-specific antiserum to Orco ${ }^{\text {S289 }}$ and show that phosphorylation at this residue is dynamically regulated by odorant exposure with concomitant modulation of odorant sensitivity. Orco ${ }^{\mathrm{S} 289}$ is phosphorylated in the sensitized state, and odorant exposure triggers dephosphorylation and desensitization without altering receptor localization. We further show that dephosphorylation of Orco ${ }^{\mathrm{S} 89}$ is triggered by neuronal activity, and not conformational changes in the receptor occurring upon ligand binding. Mutant flies unable to regulate Orco function through phosphorylation at S289 are defective for odor-guided behavior. These findings provide insight into the mechanisms underlying regulation of insect odorant receptors in vivo.

Key words: desensitization; Drosophila; olfaction; Orco; phosphorylation

\section{Significance Statement}

We have uncovered a mechanism underlying olfactory receptor sensitivity regulation in Drosophila. The phosphorylation state of $\operatorname{Orco}^{S 289}$ is altered in an odorant-dependent manner and changes in phosphorylation affect receptor sensitivity without changing subcellular localization. We show that neuronal activity triggers the phosphorylation changes and that this phenomenon is important for odorant-guided behaviors in Drosophila. This phosphorylation site is conserved in other insects, including mosquitoes, indicating this mechanism may be a target for manipulation of insect behaviors in the future.

\section{Introduction}

Sensory systems use sensitivity modulation to expand the dynamic range of sensory input. Olfactory neurons in vertebrates are well known to reduce sensitivity in the presence of an odorant stimulus to maintain the capacity to detect changes in the odorant environment (Kurahashi and Menini, 1997). It is also adaptive for an animal to desensitize to a background odorant so that changes in the odorant environment are prioritized. Behavioral desensitization has been observed in many insects, including mosquitoes, where it plays a significant role in response to repellants. For example, preexposure of mosquitoes to diethyltolua-

\footnotetext{
Received June 6, 2017; revised Aug. 4, 2017; accepted Aug. 10, 2017.

Author contributions: H.G. and D.S. designed research; H.G. and K.K. performed research; H.G. and D.S. analyzed data; H.G. and D.S. wrote the paper.

This work was supported by National Institutes of Health Grants R01DC11751 and R01DC015230 to D.S.

The authors declare no competing financial interests.

Correspondence should be addressed to Dr. Dean Smith, Department of Pharmacology, University of Texas Southwestern Medical Center, 5323 Harry Hines Boulevard, Dallas, TX 75390-9111. E-mail: dean.smith@utsouthwestern.edu.

DOI:10.1523/JNEUROSCI.1573-17.2017

Copyright (C) 2017 the authors $\quad 0270-6474 / 17 / 379465-09 \$ 15.00 / 0$
}

mide has been shown to reduce subsequent diethyltoluamide repellency (Stanczyk et al., 2013). How odorant sensitivity modulation occurs in insect olfactory neurons is not well understood.

Insects detect volatile odorants using members of three distinct ionotropic receptor families. In Drosophila, members of the gustatory receptor ( $G r$ ) family are primarily responsible for detection of tastants (Clyne et al., 2000), but two members, Gr21a and Gr63a, combine to mediate detection of $\mathrm{CO}_{2}$ (Jones et al., 2007; Kwon et al., 2007). A family of 18 Ir odorant receptors (ionotropic receptor, related to ionotropic glutamate receptors) are expressed in the Drosophila antenna that detect humidity, acids, and alcohols (Benton et al., 2009; Ai et al., 2010). However, the major Drosophila odorant receptor family is composed of 62 Or (odorant receptor) members that mediate the detection of pheromones and most volatile food odorants (Vosshall et al., 1999; Hallem and Carlson, 2004, 2006; Ha and Smith, 2006; Ronderos et al., 2014; Dweck et al., 2015; Lin et al., 2015; Pitts et al., 2016). Individual Or gene products function as "tuning" receptor subunits that form obligate heteromultimers with a highly conserved common subunit, Orco (Larsson et al., 2004; Benton et al., 2006; Sato et al., 2008; Wicher et al., 2008). Typically, a single 
A

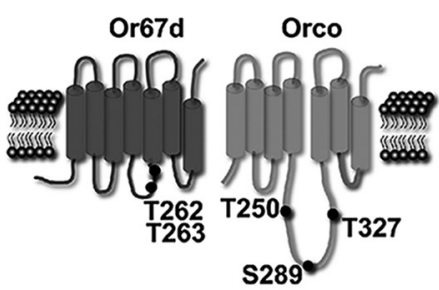

D

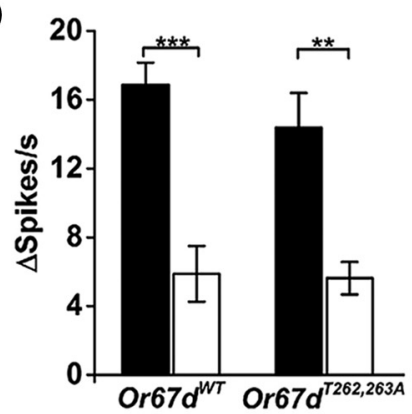

G

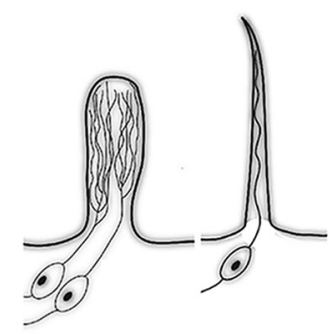

Basiconic Trichoid

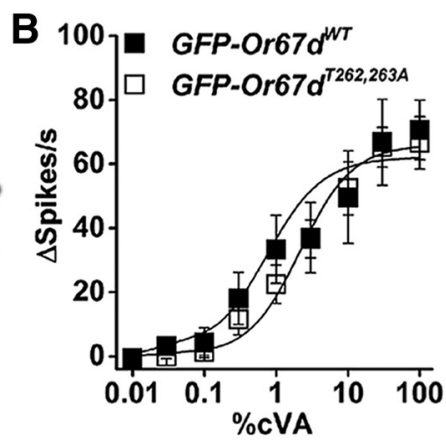

E

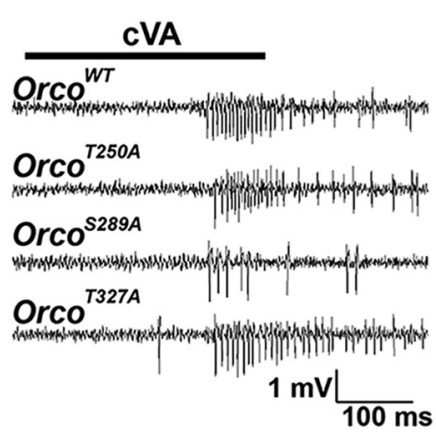

H

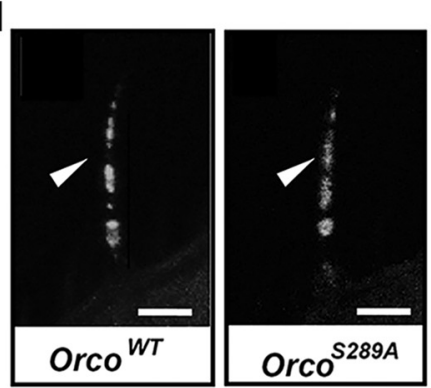

C

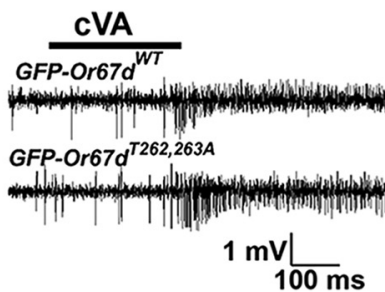

F

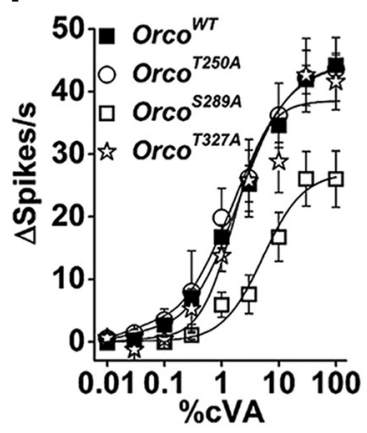

I

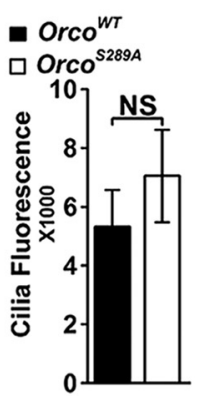

Figure 1. Orco ${ }^{5289 \mathrm{~A}}$ mutants have reduced sensitivity to odorant. A, Diagram of predicted topology of Orco (Benton et al., 2006) and Or67d showing conserved phosphorylation positions. $B$, Dose-response curves of Or67d neurons in control (black squares) and the phosphorylation double mutant (open squares). $C$, Representative traces of Or67d control and double mutants. $D$, Desensitization of wild-type (left) and Or67d double mutants (right). Filled bars represent without preexposure to cVA. Open bars represent responses after a $1 \mathrm{~h}$ cVA exposure. Both genotypes are affected by odorant preexposure (for wild-type, $p=1.09 \times 10^{-4}$; for the double mutant, $p=1.09 \times 10^{-3}$, two-tailed Student's $t$ test). Two-way ANOVA, interaction $\left(F_{(1,28)}=0.55, p=\right.$ $0.47, n=8$ for each). $\boldsymbol{E}$, Representative responses to cVA for flies expressing Orco ${ }^{\mathrm{WT}}, \mathrm{Orco}^{\mathrm{T} 250 \mathrm{~A}}, \mathrm{Orco}^{\mathrm{S289A}}$, and Orco ${ }^{\mathrm{T} 327 \mathrm{~A}} ; 100 \%$ cVA was applied. $F$, Dose-response curves for cVA comparing Orco ${ }^{\mathrm{WT}}$

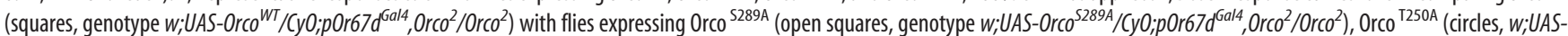

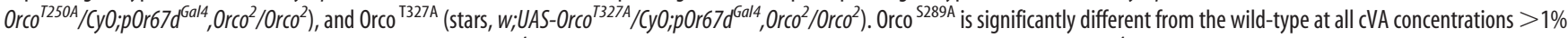
(two-tailed Student's $t$ test, $p=0.001$ for $1 \%$ cVA, $7.3 \times 10^{-4}$ for $3 \%$ cVA, 0.001 for $10 \%$ cVA, and 0.004 for $30 \%$ CVA, and $7.9 \times 10^{-4}$ for $100 \%$ cVA, $n=8$ for each). G, Cilia morphology of basiconic (left) and trichoid neurons (right). $\boldsymbol{H}$, Anti-Orco antiserum localizes $\operatorname{Orco}^{\mathrm{WT}}$ (left) and Orco ${ }^{5289 \mathrm{~A}}$ (right) to the olfactory neuron cilia of Or67d neurons. Scale bar, $5 \mu \mathrm{m}$. $\boldsymbol{I}$, Quantification of Orco ${ }^{\text {S289A }}$ and Orco ${ }^{\mathrm{WT}}$ in Or67d-expressing neuron cilia ( $n=15$ for each, $p=0.34$, two-tailed Student's $t$ test). Error bars indicate SEM. ${ }^{* *} p<0.01,{ }^{* * *} p<0.001$.

tuning receptor gene is expressed in each Orco-expressing neuron, and neurons expressing the same tuning receptor innervate the same glomerulus in the antennal lobe, similar to the wiring strategy of the vertebrate olfactory bulb (Vosshall et al., 1999, 2000).

Little is known about modulation of sensitivity to odorants in insects. In vertebrates, phosphorylation underlies desensitization in many sensory systems. Phosphorylation of G-protein-coupled receptors occurs upon receptor activation and depends on receptor kinases that detect conformational activation of the receptor (Benovic et al., 1988, 1989). Mutating the receptor kinase phosphorylation sites impairs receptor sensitivity modulation in the presence of a background stimulus, suggesting these mutant receptors are locked in a sensitized state (Morgan et al., 2014).

We evaluated whether changes in phosphorylation of Drosophila olfactory receptors underlie changes in odorant sensitiv- ity in primary olfactory neurons. We report here a mechanism responsible for reduction in odorant receptor sensitivity that occurs upon prolonged odor exposure that is biologically relevant to odor-seeking behavior.

\section{Materials and Methods}

Drosophila stocks. An isogenized strain of $w^{1118}$ was used as a wild-type control for most experiments. UAS-TNT-H (active) and UAS-TNT-V (inactive) were obtained from Sean Sweeney, and UAS-tdGFP flies were obtained from Lily Jans laboratory (Han et al., 2011). pOr59b-Gal4 and UAS-ReaChR stocks were obtained from the Bloomington Stock center. Transgenic flies were produced using standard methods (Spradling and Rubin, 1982).

Single sensillum electrophysiology. Single sensillum recordings were performed as described by Pitts et al. (2016). Filtered AC signals $(200 \mathrm{~Hz}$ to $3 \mathrm{kHz}$ ) were recorded and digitized for analysis (Autospike 32). Briefly, flies were housed in fresh vials containing standard yeast molasses food in 


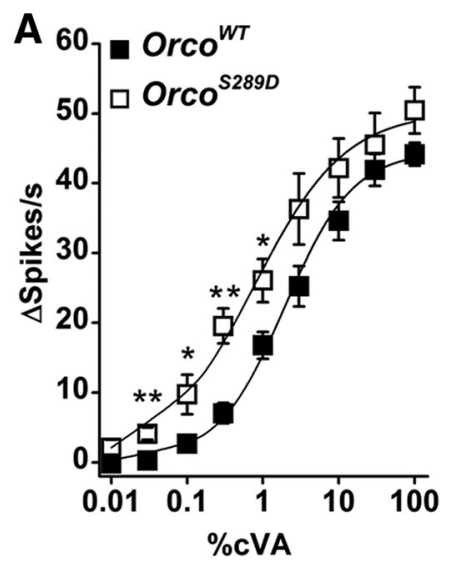

D

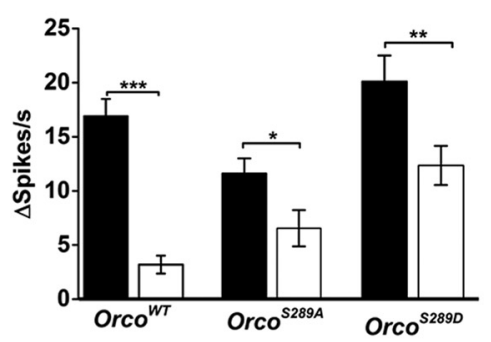

B

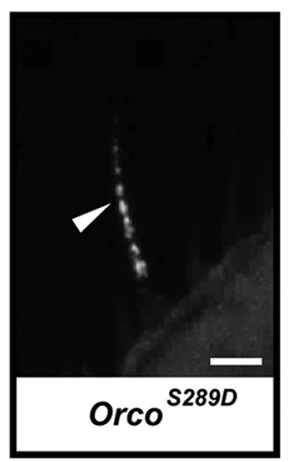

E

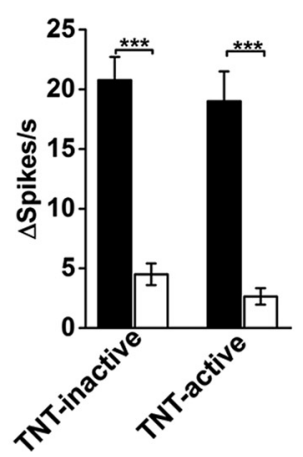

C Orco ${ }^{w T}$

$\square \operatorname{Orco}^{S 2890}$

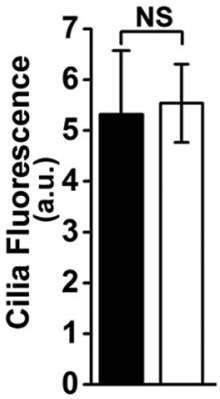

F $\square$ First $\quad \square$ Second

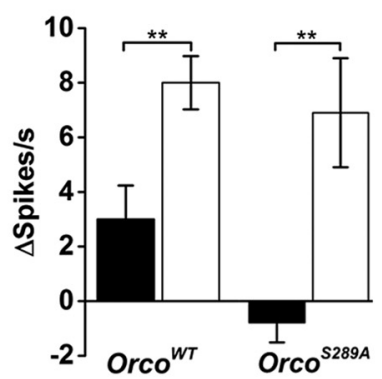

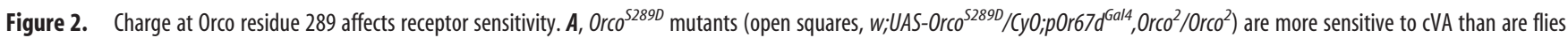
expressing wild-type Orco (black squares, w;UAS-Orco/(CyO;pOr67d ${ }^{\text {Gal }}$, Orco $^{2} / \mathrm{Orco}^{2}$ ) under the same conditions (genotypes are different by two-tailed Student's $t$ test, $p=7.5 \times 10^{-4}$ for $0.003 \%$ CVA, 0.02 for $0.1 \% \mathrm{cVA}, 3.7 \times 10^{-4}$ for $0.3 \% \mathrm{CVA}, 0.02$ for $1 \% \mathrm{cVA}, n=10$ for wild-type, $n=8$ for Orco ${ }^{52890}$ ). B, Orco ${ }^{5289 D}$ is localized to the olfactory cilia membrane. Scale bar, $5 \mu \mathrm{m}$. $C$, Orco ${ }^{52890}$ is expressed at similar levels as wild-type controls $\left(n=20, p=0.88\right.$, two-tailed Student's $t$ test). $\boldsymbol{D}$, One hour cVA preexposure desensitizes the 0r67d-expressing neurons in Orco ${ }^{W T}$ flies $\left(w ; U A S-O r c o / C y 0 ; p 0 r 67 d^{\text {Gal } 4}\right.$, Orco $/$ Orco $\left.{ }^{2}\right)$. Black bars represent no preexposure. White bars represent preexposure to $c$ VA. No odor and preexposure is significantly different $\left(p=3.61 \times 10^{-7}\right.$ by two-tailed Student's t test, $n=10$ ). Orco ${ }^{5289 A}$ mutant is also defective for desensitization after a $1 \mathrm{~h}$ cVA exposure (w;UAS-Orco $0^{5289 A} / C y 0 ; p$ Or67 $d^{\text {Gal4 }}, \operatorname{Orco}^{2} / \mathrm{Orco}^{2}, n=15, p=0.03$ by two-tailed Student's $t$ test), but desensitization is significantly different from wild-type (two-way ANOVA, wild-type and Orco ${ }^{S 289 A}, F_{(1,46)}=7.93 . p=0.007$ ). Orco ${ }^{52890}$ mutants desensitize (no odor vs preexposure, $p=0.003$, two-tailed Student's t test) but less than controls, but the difference is not significantly different from wild-type (control and Orco ${ }^{5289 D}$ not different, ANOVA, $p=0.08, n=$ 18). E, Synaptic transmission block by expression of tetanus toxin (TNT-H, active toxin) driven by the Orco promoter does not affect desensitization. Flies expressing TNT-H (w;UAS-TNT-H/pOrcoGAL4; +/TM6) show strong desensitization after CVA exposure for $1 \mathrm{~h}$ (open bars, with and without odorant different by two-tailed Student's t test, $p=0.002, n=8$ ). Desensitization is similar for TNT-V (inactive toxin, w;UAS-TNT-V/pOrco-GAL4; $+/ T M 6$, two-tailed Student's $t$ test, $p=2.39 \times 10^{-6}, n=8$ ) and is not statistically different from the active toxin (two-way ANOVA, $F_{(1,28)}=$ 0.001 . $p=0.982) . F$, Subthreshold enhancement is not significantly different between wild-type and Orco ${ }^{S 289 A}$ mutants. The first subthreshold pulse does not activate the neurons, but the neurons do respond to the second, identical pulse. The genotypes are not statistically different by two-tailed ANOVA $\left(F_{(1,20)}=1.162, p=0.294\right) .{ }^{*} p<0.05$, ${ }^{* *} p<0.01$, ${ }^{* * *} p<0.001$.

small groups before single sensillum recordings (SSRs). Odorants used in SSRs and odor exposures were of the highest purity available (SigmaAldrich; and Pherobank BV). For SSRs, $30 \mu \mathrm{l}$ of diluted or undiluted odorant was placed on a small piece of filter paper $\left(1.5 \mathrm{~cm}^{2}\right)$ inserted into a 5.75 inch Pasteur pipette, and air was passed over this filter into a constant stream $(30 \mathrm{ml} / \mathrm{s})$ of humidified air passing over the preparation. The stimulation pulse was $300 \mathrm{~ms}$ in all recordings.

Odorant exposure experiments. Male and female flies (1:1) were transferred to empty standard food vials supplemented with $200 \mu \mathrm{l}$ water for $2 \mathrm{~h}$. For single odorant exposures, a filter paper $\left(1.5 \mathrm{~cm}^{2}\right)$ with $30 \mu \mathrm{l} 10 \%$ corresponding odorant was placed in the food vials. For multipleodorant exposures, an odorant cocktail containing $30 \mu \mathrm{l} 10 \%$ ethyl acetate, $30 \mu \mathrm{l} 10 \%$ ethyl butyrate, $30 \mu \mathrm{l} 10 \%$ pentyl acetate, $30 \mu \mathrm{l} 10 \%$ octanol, and $30 \mu \mathrm{l} 10 \%$ 11-cis-vaccenyl acetate (cVA) was applied to Whatman filter paper $(1.5 \times 5 \mathrm{~cm})$ and placed in the vial. For transient exposures, the filter paper was placed in a $3 \mathrm{ml}$ syringe; and following 5 min for equilibration, syringe air was applied directly to the flies. For antiserum experiments, following specified exposure times, the flies were immediately flash frozen in liquid nitrogen and processed for sectioning. For cVA desensitization experiments, $30 \mu \mathrm{l}$ of $\mathrm{cVA}$ was added to a piece of Whatman filter paper in an empty vial for $1 \mathrm{~h}$. Controls were exposed to water. Flies were tested for responses to $1 \% \mathrm{cVA}$ by electrophysiology. For subthreshold enhancement, ethyl butyrate was used as the sub- threshold stimulus for ab2A neurons as previously described (Getahun et al., 2013), except that $10^{-7} \mathrm{v} / \mathrm{v}$ dilutions of the odorant were used. The interval between stimuli was $20 \mathrm{~s}$.

Immunocytochemistry and image analysis. Immunocytochemistry was performed on both sexes of Drosophila frozen head sections as previously described (Jin et al., 2008). Phospho-specific antibody was diluted 1:20, and anti-Orco control serum was diluted 1:300 for immunostaining. Confocal images were obtained using a Zeiss LSM 510 confocal microscope. Identical imaging settings were used for comparisons among genotypes. Cilia fluorescence intensity was quantified based on the mean pixel area (A.U. is the sum of pixel value of selected area divided by the total number of pixels) using ImageJ (http://imagej.nih.gov/ij/). The background pixel value from an identical area was subtracted. A technician blinded to genotypes performed quantification.

Generation of Orco phosphorylation site mutants. Orco mutants were produced using Q5 Site-Directed Mutagenesis Kit (NEB) on a wild-type Orco cDNA or UAS $>$ GFP-Or67d (Benton et al., 2007) for Or67d. Complete Sanger sequencing of the entire receptor sequence confirmed the mutations.

Primers used for mutagenesis were as follows: $\operatorname{Orco}^{\text {S289A }}, 5^{\prime}$-GGGCATCTACGCCTCGAAAGCGG-3' , 5' -GACATGTCCATGTCGGTG-3'; $\operatorname{Orco}^{\text {S289D }}, 5^{\prime}$-GACATGTCCATGTCGGTG-3'， 5' -GGGCATCTACGACTCGAAAGCGG-3'; $\operatorname{Orco}^{\text {T250A }}, 5^{\prime}$-CTCGCTGGACGCCTACAGGC- 
CCA-3', 5'-GCGGACAGCTCCATCAGCG-3'; $\operatorname{Orco}^{T 327 A}, 5^{\prime}$-CAACGGGCTGGCCAAAAAGCAGG-3', 5'-GGATTAGCGCCGTTCACC3'; and $\operatorname{Or}^{\prime} 67 d^{T 262,263 A}, 5^{\prime}$-GAATTCATGGTGAGCAAGGGCGA-3', 5' -CTCGAGTTATCCCAAATAGTTCATCAAC- $3^{\prime}$.

Generation of Orco S289 phospho-specific antibody. The phospho-specific antibody was custom synthesized (Genemed Synthesis). The phosphorylated peptide DMDMSGIYS[p] SKADWGAQC was synthesized and used for antibody production and affinity purification. The unphosphorylated peptide was synthesized and used to remove antipeptide antibodies that were not phospho-specific, generating anti-Orco serum.

Optogenetic experiments. The light source used for optogenetic stimulation was described by Inagaki et al. (2014). Both sexes of new enclosed flies ( w;pOrco-Gal4/UAS-ReaChR) were collected and housed in the dark on Nutri-Fly media for $6 \mathrm{~d}$ supplemented with $1 \%$ retinal stock solution (40 mm all-trans-retinal, Sigma). High-power Rebel LEDs (627 nm, Luxeon) were placed at $12 \mathrm{~cm}$ distance from the flies in food vials for $1 \mathrm{~h}$. Light-stimulated flies or dark-reared controls were flash-frozen in liquid nitrogen before sectioning. Activation of the olfactory receptor neurons by the red light conditions above was confirmed by SSR.

Behavior experiments. A total of 150 flies of both sexes were starved in a humidified chamber $\left(30 \mathrm{~cm}^{3}\right)$ for $8 \mathrm{~h}$. Eight traps were prepared for each odorant (apple cider vinegar $[\mathrm{ACV}]$, or orange juice) consisting of $13 \times 100 \mathrm{~mm}$ borosilicate culture tubes (Fisher) containing $2.5 \mathrm{ml}$ of attractant diluted with $2.5 \mathrm{ml}$ of $1 \%$ agarose (Sigma) with an Eppendorf tube in the opening. A $2 \mathrm{~mm}$ hole was drilled through the bottom of the Eppendorf tube to allow flies access to the trap. The traps were introduced into the chamber with the flies and left overnight in the dark. Attractants were 50\% ACV (Bragg) or orange juice (Simply Orange). The flies were preexposed to $50 \% \mathrm{ACV}$ vapor (3 $\mathrm{L} / \mathrm{min}$ ) for $1 \mathrm{~h}$ before introduction of the traps, and ACV vapors were continued overnight for measurements in the presence of background odorants.

Experimental design and statistical analysis. Two- to 6-d-old flies were used for electrophysiological recordings. Two- to 6-d-old male and female flies were used for immunostaining and behavior tests. For behavior, flies were iso-

lated at least $24 \mathrm{~h}$ before the test to avoid the anesthesia effects of $\mathrm{CO}_{2}$. The two-tailed Student's $t$ test was used to test for statistical significance using Origin 8.0. For multiple sample comparisons, one-way and twoway ANOVA with post hoc Tukey's multiple comparisons was used (SPSS package).

\section{Results}

Orco phosphorylation at S289 affects odorant responses

Using multiple sequence alignment and the NetPhos 3.1 phosphorylation prediction algorithm (Blom et al., 1999), we identified conserved, potential phosphorylation sites for Or/Orco regulation located on the intracellular domains. Initially, we focused on Or67d/Orco odorant receptor subunits that mediate detection of the male-specific pheromone cVA (Ha and Smith,
Anti-Orco
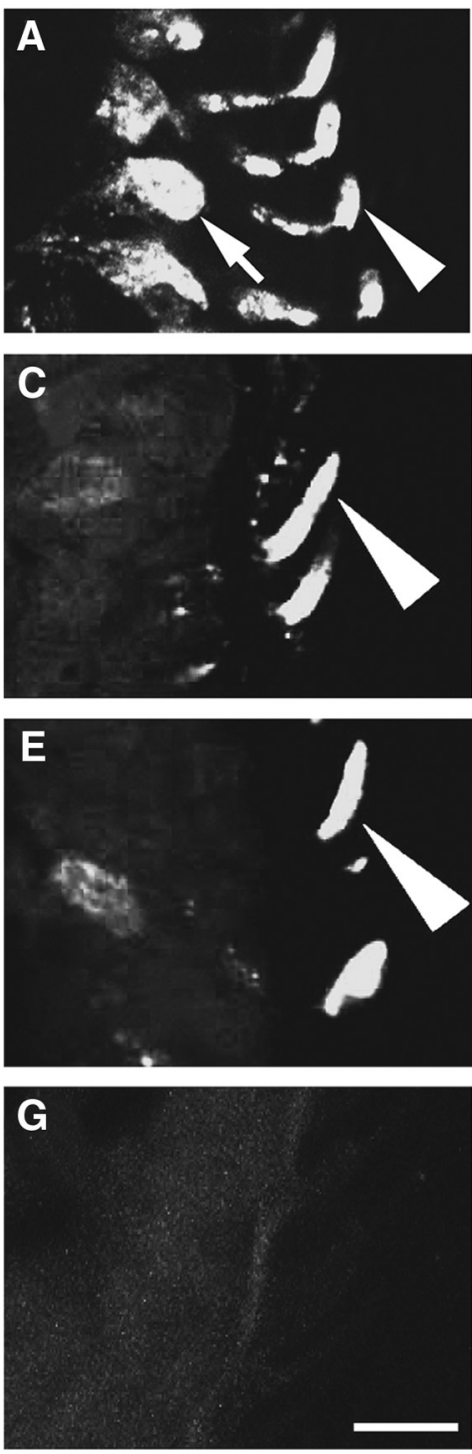

Anti-Phospho
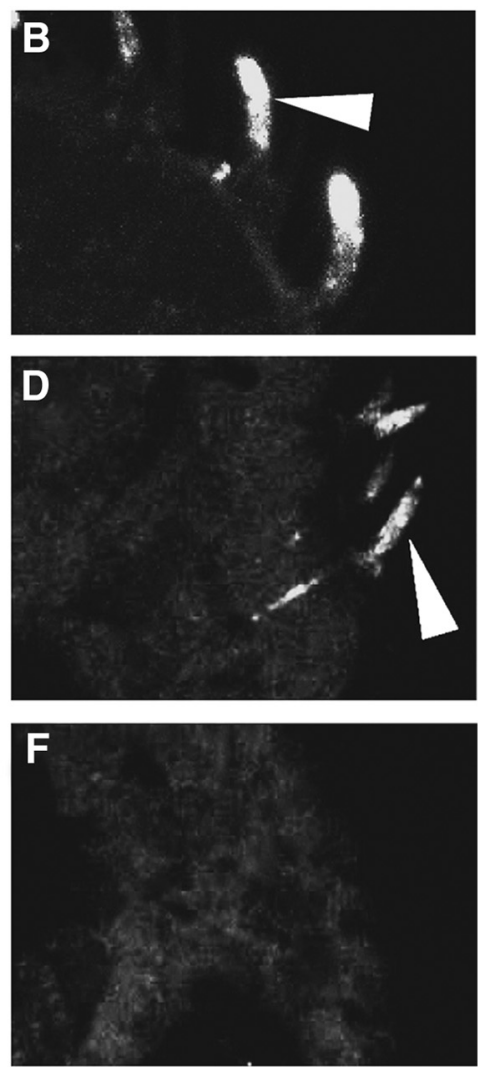

H

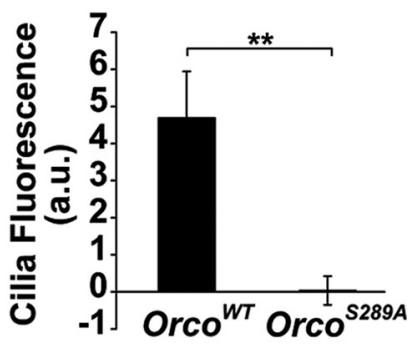

Figure 3. Phospho-specific antiserum to Orco S289 localizes phosphorylated Orco to the olfactory neuron cilia and has no cross-reaction to $\operatorname{Orco}^{5289 A} . A$, The localization of Orco in $w^{1118}$ antenna. Arrowhead indicates cilia. Arrow indicates the cell body. B, S289 phospho-specific antiserum labels only the olfactory cilia in $w^{1118}$ antenna (arrowhead). C, Expression of a wild-type Orco CDNA in Orco olfactory neurons ( $w$; UAS-Orco ${ }^{W T} /$ pOrco-Gal4; Orco $^{2}$ ). D, S289 phospho-specific antiserum detects Orco in olfactory cilia in Orco ${ }^{W T}$ antenna. E, Expression of $\operatorname{OrCO}^{\text {S289A }}$ (W;UAS-OrCO ${ }^{5289 A} /$ pOrco-Gal4; $\operatorname{OrcO}^{2}$ ) is expressed in the cilia as detected with anti-Orco. $\boldsymbol{F}$, Orco $^{5289 \mathrm{~A}}$ mutant protein is not detected by the phospho-specific antiserum. $\boldsymbol{G}$, Anti-Orco (for total Orco detection) detects no signal in $\operatorname{Orco}^{2}$ mutants. $\boldsymbol{H}$, Quantification of $\$ 289$ phosphorylation in $\operatorname{Orco}^{W T}$ and $\operatorname{Orco}^{5289 A}(n=10$, significantly different by two-tailed Student's $t$ test, $p=0.002$ ). Scale bar, $10 \mu \mathrm{m} .{ }^{* *} p<0.01$.

2006; Kurtovic et al., 2007; Jin et al., 2008). We evaluated three strong candidate phosphorylation sites on the intracellular domain of Orco (Fig. 1A) and two conserved candidate phosphorylation sites on the predicted intracellular domain of the Or67d tuning receptor subunit.

We first set out to test whether the Or67d tuning receptor subunit phosphorylation sites were candidates for modulation. We mutated T262 and T263 residues in Or67d to alanine (see Materials and Methods) and expressed these double-mutant receptors in at 1 neurons of flies lacking the endogenous Or67d gene (Kurtovic et al., 2007). Desensitization can be rapid, operating in tens of milliseconds modulating neuronal responses over the course of a single stimulus (Cao et al., 2016), or slow, operating over minutes to readjust the gain of the neuron (Das et al., 2011). 

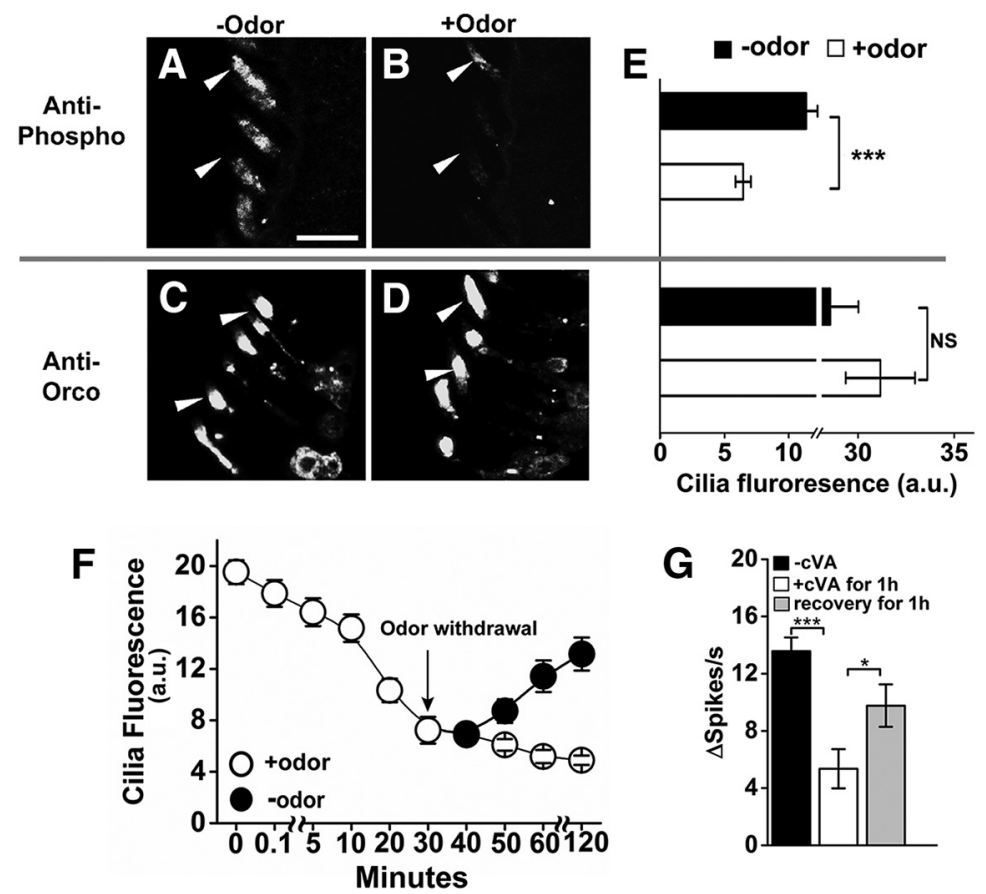

Figure 4. Odorant stimulation reduces phospho-specific antiserum immunoreactivity. $\boldsymbol{A}, \boldsymbol{B}$, Representative images of phosphorylated Orco ${ }^{5289}$ with and without a $1 \mathrm{~h}$ odorant preexposure. Scale bar, $10 \mu \mathrm{m}$. C, D, Representative images of total Orco localization in wild-type cilia without $(\boldsymbol{C})$ or with $(\boldsymbol{D})$ odorant preexposure. $\boldsymbol{E}$, Top, Phospho-Orco signal is significantly different in the presence of odor preexposure ( $n=40, p=1.55 \times 10^{-5}$, two-tailed Student's t test). Bottom, Total Orco levels in the cilia are not significantly different with or without odorant preexposure $(n=20, p=0.27$, two-tailed Student's $t$ test). The antisera results are different by two-way ANOVA $\left(F_{(1,116)}=11.174 . p=0.001\right)$. $\boldsymbol{F}$, Time course of odorant-induced dephosphorylation and recovery of $\operatorname{Orco}^{5289}$ ( $n=20$ for each time point). $\mathbf{G}$, Desensitization of $w^{1118}$ Or67d neurons after $1 \mathrm{~h}$ cVA exposure and $1 \mathrm{~h}$ recovery after $\mathrm{CVA}$ withdrawal ( $n=8$ for each treatment). The differences are statistically different between no odor and $1 \mathrm{~h}$ preexposure $\left(p=2.24 \times 10^{-4}\right.$, two-tailed Student's $t$ test, $\left.n=8\right)$, and from $1 \mathrm{~h}$ preexposure to $\mathrm{CVA}$ and after $1 \mathrm{~h}$ recovery $(p=$ 0.047 , two-tailed Student's $t$ test, $n=8$ ). Data are mean \pm SEM. ${ }^{*} p<0.05,{ }^{* * *} p<0.001$.

The cVA dose-response curves from wild-type flies compared with those expressing the Or67d phosphorylation doublemutant receptors, in lieu of endogenous Or67d receptors, had no significant differences in cVA dose-response curves (Fig. 1A,B). Similarly, cVA-induced responses showed no difference in latency or modulation over the course of a stimulus between the two genotypes (Fig. 1C). Finally, exposure of wild-type or Or67d phosphorylation mutants to a prolonged cVA stimulus resulted in a reduction of responses that was not statistically different between the genotypes (Fig. 1D). Therefore, loss of these potential tuning receptor phosphorylation sites does not affect receptor sensitivity.

We next tested the biological importance of the Orco candidate phosphorylation sites (Fig. 1A). We individually mutated each candidate phosphorylation site on the intracellular domain and generated transgenic flies expressing each engineered version in the $\mathrm{OrCo}^{2}$-null genetic background (Larsson et al., 2004). In these flies, the transgenic version of Orco essentially replaces the wild-type gene product. We also expressed a wild-type Orco cDNA transgene as a control.

Mutation of threonine 250 (T250) or threonine 327 (T327) to alanine did not significantly alter cVA dose-response curves or rapid desensitization compared with the wild-type Orco expressed in primary olfactory neurons (Fig. $1 E, F$ ). There was no difference in cVA sensitivity modulation in the presence of background cVA compared with the wild-type control. However, mutation of serine 289 (S289) to alanine (S289A) resulted in a striking reduction in cVA sensitivity, especially apparent at higher cVA concentrations (Fig. 1E,F).
The reduced odorant sensitivity in Orco ${ }^{\text {S289A }}$ mutants could result from defective expression or subcellular localization of the mutant protein. To address this possibility, we used Orco antiserum to quantitate expression of Orco ${ }^{\mathrm{S} 289 \mathrm{~A}}$ and wild-type control in Or67d neurons. Or67d is expressed in at 1 neurons that have a single, unbranched cilium, whereas basiconic neurons typically have highly branched neurons (Fig. 1G). We found that expression levels of Orco ${ }^{\mathrm{S} 289 \mathrm{~A}}$ and wild-type Orco in frozen tissue sections are not significantly different (Fig. $1 H, I$ ). Similarly, Orco ${ }^{\text {S289A }}$ localization in the cilia of the olfactory neurons appears identical to the control. Therefore, reduced expression or abnormal localization of Orco ${ }^{\text {S289A }}$ does not account for the reduction in cVA sensitivity in flies expressing this mutant version of Orco.

S289A has reduced odorant sensitivity, so perhaps introducing a charged residue at position 289 could mimic the phosphorylated state and have the opposite effect of the alanine mutation. We replaced S289 with an aspartate residue (Orco ${ }^{\text {S289D }}$ ) and expressed this in the Orco $^{2}$-null background. Figure $2 \mathrm{~A}$ shows that the aspartate substitution results in a small but statistically significant enhancement of cVA sensitivity compared with the wildtype Orco control. Quantification of expression levels and immunolocalization of Orco $^{\text {S289D }}$ and Orco wild-type in Or67d neurons revealed no differences in expression level or localization of Orco ${ }^{\text {S289D }}$ in the chemosensory cilia (Fig. 2 B,C). We concluded that Orco odorant receptor sensitivity is altered by charges at Orco S289, and this residue might be an important target for regulation of Orco sensitivity by phosphorylation in vivo.

We next compared $\operatorname{Orco}^{S 289 A}$ and wild-type control flies for differences in sensitivity modulation to a background odorant. We preexposed flies to cVA for $1 \mathrm{~h}$ and measured cVA doseresponse curves. Figure $2 D$ shows that wild-type flies have a striking reduction in cVA sensitivity following a prior exposure to cVA, consistent with desensitization. This desensitization is cell autonomous and does not result from postsynaptic feedback inhibition onto the primary olfactory neurons (Das et al., 2011; Cafaro, 2016) because blocking synaptic transmission with tetanus toxin has no effect on the sensitivity change (Fig. 2E). Orco ${ }^{\text {S289A }}$ mutants showed reduced cVA sensitivity compared with wild-type controls, and preexposure to cVA had less effect on the cVA responses from these mutants relative to wild-type controls (Fig. 2D). This is consistent with the idea that $\operatorname{Orco}^{5289 A}$ mutants are not able to phosphorylate this residue and are in a low sensitivity state, with a limited ability to undergo further desensitization.

\section{Phospho-specific antiserum reveals dynamic regulation of Orco $^{\text {S289 }}$}

To evaluate the dynamics of Orco ${ }^{\mathrm{S} 289}$ phosphorylation in vivo, we generated a phospho-S289 Orco-specific antiserum (see Materials and Methods). We examined frozen antenna tissue sections 
from wild-type and flies expressing Orco $^{\text {S289A }}$ in the Orco $^{2}$ mutant background. Interestingly, in wild-type controls, phospho-specific antiserum identifies a strong signal in the chemosensory cilia but little signal in the cell body (Fig. 3B), whereas anti-Orco antiserum (which recognized Orco protein regardless of its phosphorylation state) detected Orco protein in both subcellular compartments. This indicates that phosphorylated Orco ${ }^{\mathrm{S} 289}$ is primarily localized to the chemosensory cilia. Flies expressing $\mathrm{Orco}^{S 289 A}$ in lieu of wild-type Orco express equivalent levels of Orco protein detectable with the antiOrco antiserum (Fig. 3E), but there is no phospho-specific antibody signal present in the cilia, confirming the specificity of the phospho-S289 Orco antiserum (Fig. $3 F, H)$.

We next set out to determine whether phosphorylation at S289 is altered by odorant exposure. Previous studies have suggested that odorants increase phosphorylation of Orco, and this is important for subthreshold sensitization where a weak odorant pulse fails to activate olfactory neurons on the first pulse but does activate upon the second identical pulse. The site where these modifications occur was not established (Getahun et al., 2013, 2016). We exposed wild-type flies to an odorant cocktail predicted to activate most classes of olfactory neurons (Hallem and Carlson, 2004, 2006). Flies exposed to a brief pulse of this cocktail showed no significant increase or decrease in the phospho-specific antibody signal. However, when we exposed flies to the odorant cocktail for longer periods, we observed a significant reduction in Orco ${ }^{\text {S289 }}$ phosphorylation compared with flies without odorant exposure (Fig. $4 A, B, E$ ).

Given the cilia-specific localization of phospho-S289 Orco, one possibility is that phosphorylation at S289 regulates receptor trafficking, and dephosphorylation results in trafficking of Orco receptors out of the cilia and into the cell body. To examine this possibility, we repeated the odorant exposure experiments but used anti-Orco to localize total Orco protein (Fig. 4C-E). Remarkably, this antiserum revealed that total Orco levels are unchanged in the cilia following odorant exposure. Therefore, dephosphorylation of Orco at S289 occurs within the dendritic cilia upon odorant stimulation, and this does not affect receptor trafficking.

We next examined the dynamics of S289 phosphorylation upon odorant exposure. Odorant induces a steady-state decrease in phospho-S289 Orco within a few seconds that becomes statistically significant after several minutes and is near maximal after $30 \mathrm{~min}$ of odor exposure (Fig. $4 F$ ). Removal of the odorant source results in a gradual recovery of phosphorylation that correlates with restoration of odorant sensitivity (Fig. $4 F, G$ ). Thus, this dephosphorylation/phosphorylation cycle operates over a $0.01,{ }^{* * *} p<0.001$.
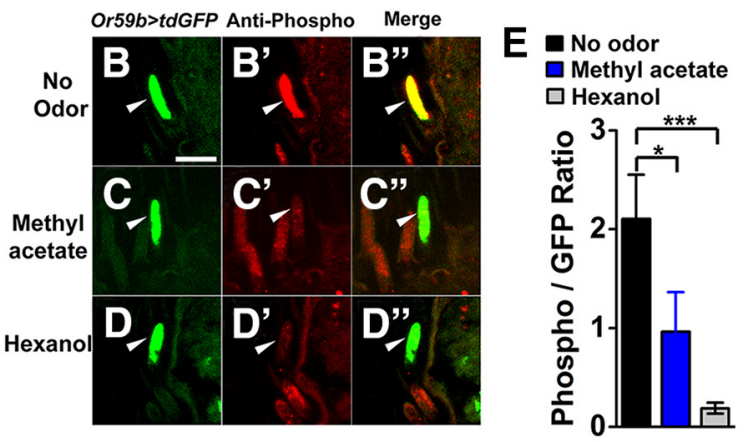

G

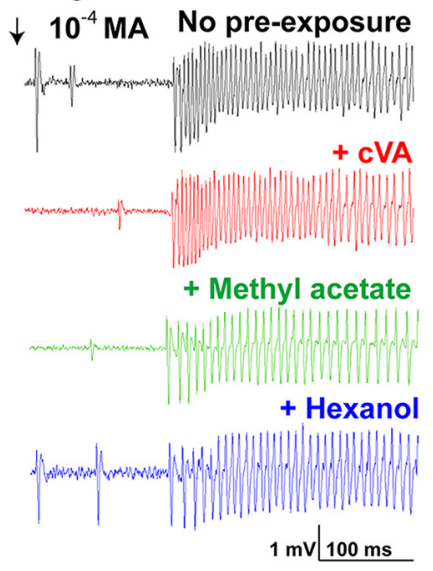

Figure 5. Odorant-stimulated dephosphorylation of 0 rco ${ }^{5289}$ in a defined neuron. $\boldsymbol{A}$, Representation of ab2 sensillum showing the intermingled dendrites of the $0 \mathrm{r} 59 \mathrm{~b}$ and $0 \mathrm{r} 85 \mathrm{a}$ neurons. Or59b neurons respond to hexanol and methyl acetate, whereas $0 \mathrm{r} 85 \mathrm{a}$ quantify phosphorylated 0 rco ${ }^{5289}$ in the cilia with and without odorant exposure. B-D, GFP-labeled ab2A neuron cilia ( $w ;+/ C y 0$; UAS-td-GFP/p0r59b-Gal4) to identify ab2 sensilla. Scale bar, $5 \mu \mathrm{m} . \boldsymbol{B}^{\prime}, \boldsymbol{C}^{\prime}, \boldsymbol{D}^{\prime}$, Phospho-specific antiserum immunoreactivity in cilia with no odor preexposure $\left(\boldsymbol{B}^{\prime}\right)$, following methyl acetate preexposure $\left(\boldsymbol{C}^{\prime}\right)$, or following hexanol preexposure ). $\boldsymbol{B}^{\prime \prime}, \boldsymbol{C}^{\prime \prime}, \boldsymbol{D}^{\prime \prime}$, Merged images colocalizing GFP and phospho-specific antiserum signal in ab2A neuron cilia without odorant

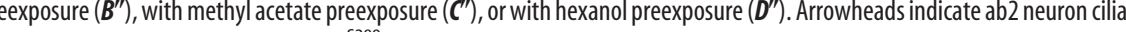
列 作 Methyl acetate sensitivity is similar between no odorant preexposure (black squares) or cVA preexposure (negative control, red circles). Methyl acetate sensitivity is reduced both by preexposure to methyl acetate (green diamonds) and by preexposure to hexanol (blue stars). No odor versus $10^{-5}$ methyl acetate preexposure for $1 \mathrm{~h}(p=0.011$, two-tailed Student's $t$ test). $p=0.028$ for no odor versus $10^{-4}$ methyl acetate. $p=0.005$ for no odor versus $10^{-3}$ methyl acetate. Statistical significance for hexanol is of methyl acetate sensitivity of 0 r59b neurons with and without prior odorant exposure. Data are mean \pm SEM. ${ }^{*} p<0.05,{ }^{* *} p<$

period of minutes of odor exposure and is distinct from rapid attenuation that occurs during an acute odor exposure (Cao et al., 2016).

Not all receptors are activated by this odor cocktail, and some receptors may only have partial activation. To more accurately assess the effect of odorant exposures on specific classes of olfactory neurons, we examined phosphorylation and sensitivity changes for olfactory neurons contained within the ab2 sensilla in response to specific activating odorants. The two neurons encased within this sensillum express either tuning odorant receptor Or59b or Or85a (Couto et al., 2005). Both receptors are activated by $10 \%$ hexanol, but only the Or $59 \mathrm{~b}$ receptor neurons are activated by methyl acetate (Hallem and Carlson, 2006). To identify ab2 sensilla, we expressed membrane-anchored GFP in Or59b-expressing neurons (Fig. 5B-D). We exposed these flies to methyl acetate or hexanol and assessed Orco ${ }^{\text {S289 }}$ phosphoryla- 


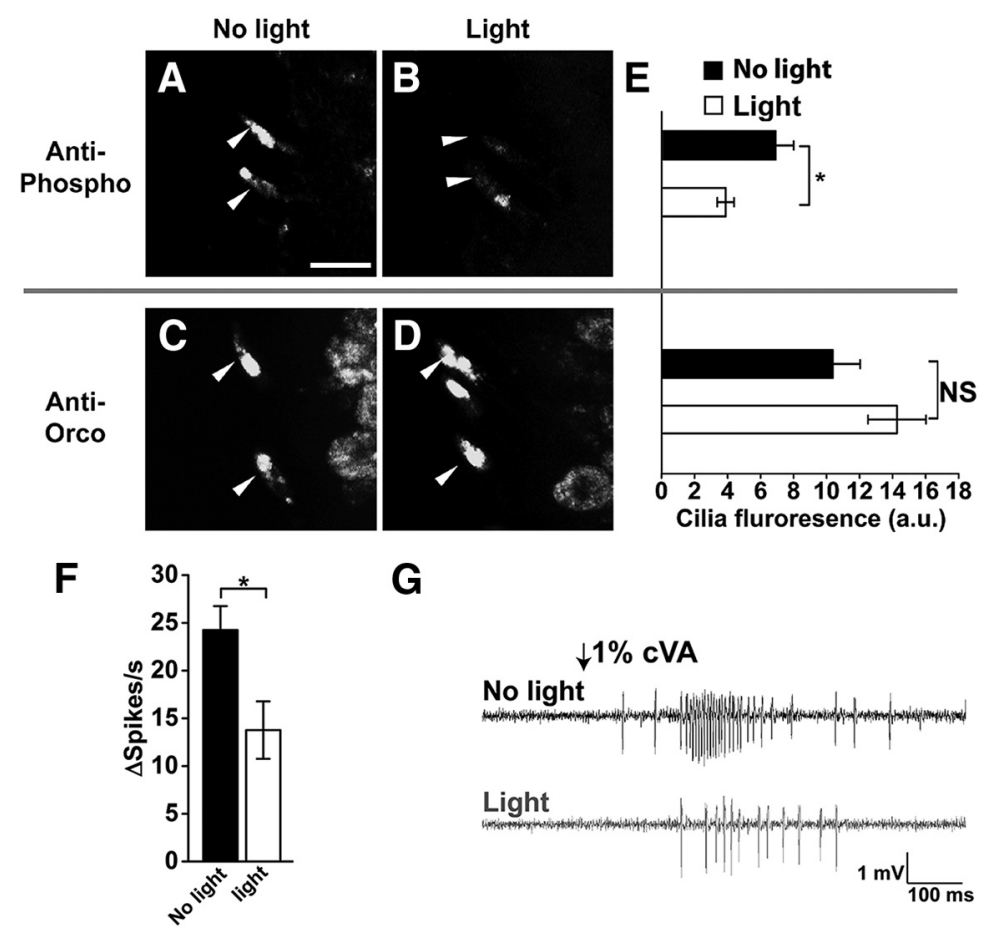

Figure 6. Activation of olfactory neurons using ReaChR red-shifted channelrhodopsin instead of odorants also results in dephosphorylation of $\operatorname{Orco}^{5289} . A, B$, Representative images of phosphor-Orco ${ }^{5289}$ in the cilia (arrowheads) with and without light stimulation (genotype w;UAS-ReaChR/pOrco-Gal4;+/TM6B). Scale bar, $10 \mu \mathrm{m}$. C, D, Representative images of total Orco localization in the cilia with and without light stimulation. $\boldsymbol{E}$, Top, Quantification of phospho-Orco ${ }^{5289}$ in the cilia $(n=15, p=0.046$ by two-tailed Student's $t$ test). Bottom, Quantification of total Orco in the cilia ( $n=7, p=0.13$ by two-tailed Student's $t$ test). Results between antisera are different by two-way ANOVA $\left(F_{(1,40)}=8.462, p=0.006\right)$. $\boldsymbol{F}$, Sensitivity to CVA is significantly reduced following red light exposure ( $n=8, p=0.02$ by two-tailed Student's $t$ test). ${ }^{*} p<0.05$. $\mathbf{G}$, Representative traces of responses to CVA with and without preexposure. Data are mean \pm SEM.

tion with the phospho-specific antiserum. Figure 5 shows that, in the absence of odorant, the intermingled, branched dendritic cilia of Or59b and Or85a neurons (Fig. 5A) have robust phosphospecific signals (Fig. 5 $B^{\prime}$ ). However, when exposed to hexanol (which activates both neurons), the Orco ${ }^{\text {S289 }}$ phosphorylation signal is greatly reduced, whereas the GFP signal remains (Fig. $\left.5 D, D^{\prime}, D^{\prime \prime}\right)$. Using the GFP signal to normalize the hexanolinduced change in phospho-specific antibody signal, we established that odorant exposure resulted in a 10 -fold reduction in phospho-S289 in the cilia compared with unexposed neurons (Fig. $5 E$ ). As expected, selective activation of Or $59 \mathrm{~b}$ neurons with methyl acetate reduced the phospho-Orco signal by $50 \%$ consistent with the dendritic branches of both neurons contributing to the cilia signal, but with reduction of the phospho-specific signal only in the Or59b neurons (Fig. $5 C, C^{\prime}, C^{\prime \prime}$ ).

We compared the odorant sensitivity of Or59b olfactory neurons to methyl acetate following an identical $1 \mathrm{~h}$ exposure to this odorant. The dose-response curves in Figure $5 F$ show that Or59b neurons preexposed to methyl acetate undergo a reduction in methyl acetate sensitivity and reduced spiking frequency on SSR traces (Fig. 5G). Preexposure of these neurons to hexanol also resulted in desensitization of Or59b neurons to methyl acetate. (Fig. $5 F$ ).

Orco dephosphorylation is triggered by neuronal activity In many G-protein-coupled receptor systems, conformational changes in the receptor occurring upon ligand binding result in phosphorylation by a receptor kinase (Weller et al., 1975; Benovic et al., 1988, 1989; Hausdorff et al., 1990). To determine whether odorant exposure is required for changes in Orco phosphorylation at S289, we activated olfactory neurons in the absence of odorants by expressing the red-shifted channelrhodopsin, ReaChR (Lin et al., 2013) in olfactory neurons using the Orco promoter and examined Orco phosphorylation. Light activation of olfactory neurons induced a similar loss of phosphorylation at S289 that we observed upon odorant exposure (Fig. 6A, B,E). ReaChR activation of olfactory neurons also triggered desensitization to subsequent odorant stimulation (Fig. $6 F, G$ ). Light-stimulated neuronal activation did not alter the subcellular localization of Orco (Fig. 6C-E). Therefore, dephosphorylation of Orco ${ }^{\text {S289 }}$ results from activation of the olfactory neurons, and not by odorant ligandinduced conformational change in the Or/Orco receptor. This is consistent with the cross-adaptation we observed with hexanol preexposure on Or59b neurons, resulting in reduced sensitivity to methyl acetate.

\section{Food-seeking behavior is altered in} Orco phosphorylation mutants

To begin to explore the biological significance of Orco $^{\text {S289 }}$ phosphorylation, we tested the ability of wild-type and $\operatorname{Orco}^{\text {S289 }}$ mutant flies to locate food in the presence or absence of background odor (Fig. 7A). Wild-type flies are normally strongly attracted to traps containing ACV. However, if the wild-type flies are preexposed to ACV vapors in the arena, there is a highly significant reduction in entry of ACV traps (Fig. 7B). This effect is odor-specific because the ability to locate orange juice traps was unimpaired by ACV background odorant (Fig. 7C). Orco ${ }^{S 289 A}$ and $\mathrm{OrCO}^{S 289 D}$ mutants were significantly more likely to enter ACV traps in the presence of background ACV than wild-type controls (Fig. 7B). Therefore, the ability to modulate phosphorylation at S289 is important for the ability to desensitize to a background odorant.

\section{Discussion}

We have identified a conserved phosphorylation site in Orco that is important for modulating odorant receptor sensitivity in vivo to background odorant exposure operating over a scale of minutes. Orco ${ }^{\text {S289 }}$ is in the phosphorylated state in the absence of background odorant, and prolonged odorant exposure induces a steady-state dephosphorylation at this site in vivo, reducing odorant sensitivity. Changes in phosphorylation at this residue occur within the olfactory cilia, and the resulting effect on sensitivity does not involve receptor trafficking.

The mechanism we describe here is intrinsic to the olfactory neurons and is not a circuit property mediated by feedback from inhibitory neurons activated by synaptic activation of downstream neurons (Das et al., 2011; Tachibana et al., 2015; Cafaro, 2016) because desensitization in the primary olfactory neurons is unaffected when synaptic transmission is blocked. Other modifications are likely to occur on Orco in response to odorant exposure that affect sensitivity, as we observe residual desensiti- 
A
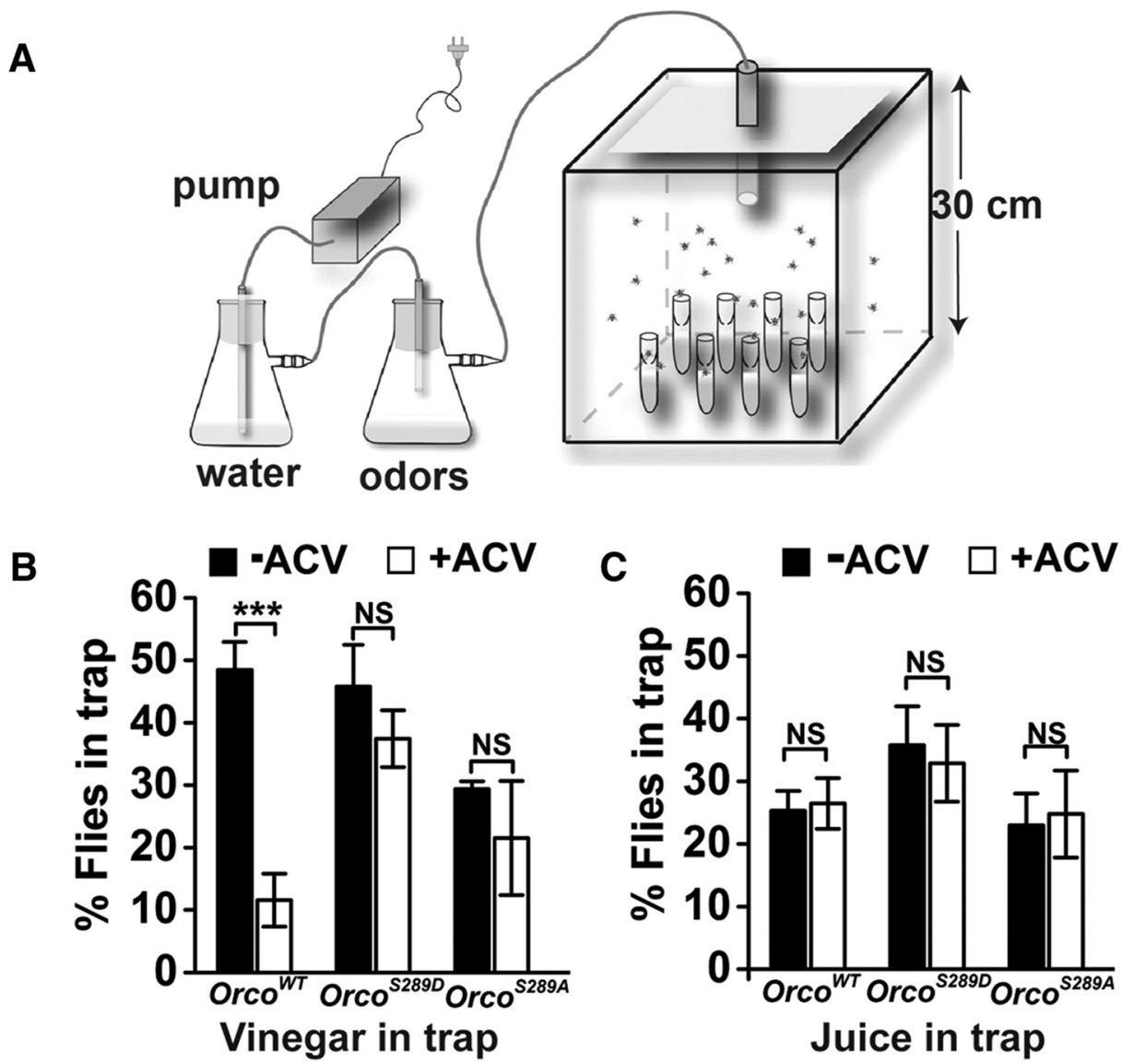

Figure 7. Regulation of Orco at $S 289$ affects food-seeking behavior in the presence of a background odor. $\boldsymbol{A}$, Schematic diagram of the behavior trap assay. $\boldsymbol{B}$, Preexposure to ACV (open bars) significantly reduces the number of Orco ${ }^{W T}$ flies in traps containing $50 \% \mathrm{ACV}\left(n=5, p=3.23 \times 10^{-4}\right.$ by two-tailed Student's $t$ test). Preexposure to ACV has less effect on Orco ${ }^{52890}$ ( $n=5, p=$ $0.33)$ or $\operatorname{Orco}^{S 289 A}(n=5, p=0.42)$ attraction to ACV traps compared with control. ANOVA is significant between genotypes $\left(F_{(1,16)}=4.79 p=0.044\right.$ between wild-type and $\operatorname{Orco} 0^{5289 A}$, and $F_{(1,16)}=8.40, p=0.01$ between wild-type and $\left.\operatorname{Orco}^{5289 D}\right)$. C, Preexposure of $50 \%$ ACV has no significant effect on the number of flies attracted to traps containing orange juice $(n=5, p=0.82$ for $\operatorname{Orco}^{W T}, p=0.75$ for Orco ${ }^{5289 D}$, and $p=0.84$ for $\operatorname{Orco}^{5289 A}$ by two-tailed Student's $t$ test). Two-way ANOVA, no difference between genotypes $\left(F_{(2,24)}=0.11 . p=0.897\right)$. ${ }^{* * *} p<0.001$. Data are mean \pm SEM.

zation in the S289A and S289D mutants. Nevertheless, the ability to regulate phosphorylation at S289 is an important component of sensitivity modulation.

Previous studies have reported increased Orco phosphorylation upon odorant stimulation as underlying subthreshold enhancement. PKC53E and PKC delta were reported to mediate these effects (Getahun et al., 2013). We did not observe any increase in Orco ${ }^{\text {S289 }}$ phosphorylation upon odorant exposure, and subthreshold enhancement is unaffected in $\mathrm{Orco}^{\text {S289A }}$ mutants (Fig. $2 F$ ), revealing that this phenomenon is not mediated by steady-state increases in S289 phosphorylation. However, phosphorylation at other potential Orco phosphorylation sites is not excluded by our study. S289 is highly conserved in Orco from moths, flies, and mosquitoes, consistent with an important role in sensitivity modulation. Using a modulatory site on the conserved subunit shared by all Or odorant receptors allows for a common regulatory mechanism that is independent of tuning receptor.

Phospho-specific antiserum showed that Orco ${ }^{\mathrm{S} 289}$ is phosphorylated in the cilia of the olfactory neurons in vivo, and neuronal activation occurring upon odorant exposure triggers dephosphorylation and sensitivity reduction. This could occur through activation of a phosphatase, such as calcineurin, or by inhibition of a constitutively active kinase present in the cilia. It is of great interest to identify the enzymes that mediate these events in Drosophila olfactory cilia because they are potential targets for olfactory behavior modification in pathogenic species, and screens to identify these enzymes are underway.

The ability to modulate sensitivity is important for foodseeking behavior in the presence of a background stimulus. We were somewhat surprised that the $\operatorname{Orco}^{S 289 D}$ mutants were not overly attracted to the ACV in the trap assays. However, the enhanced sensitivity in the dose-response curves is small and therefore might not be reflected in these assays. It seems likely that the major function of this regulatory site is to lower sensitivity in response to the presence of activating odors. Indeed, wild-type flies are able to ignore traps containing a background odorant, but $\mathrm{Orco}^{S 289 A}$ and $\mathrm{OrCO}^{\text {S289D }}$ mutants are not. This could have advantages in the wild for flies seeking new food sources.

We describe a mechanism in Drosophila olfactory neurons that uses dephosphorylation of Orco ${ }^{\text {S289 }}$ to desensitize odorant responses to prolonged odorant stimulation. Ion channels, including the acetylcholine receptor and L-type calcium channels, use phosphorylation to recover from chronic activation (Lee et al., 2015; Weiss and Dascal, 2015), but less understood is the role of dephosphorylation in desensitization of ion channels. Future work will be directed toward identifying the enzymes mediating these effects that could result in new approaches to manipulate odorant sensitivity and insect behaviors. 


\section{References}

Ai M, Min S, Grosjean Y, Leblanc C, Bell R, Benton R, Suh GS (2010) Acid sensing by the Drosophila olfactory system. Nature 468:691-695. CrossRef Medline

Benovic JL, Bouvier M, Caron MG, Lefkowitz RJ (1988) Regulation of adenyl cyclase-coupled beta-adrenergic receptors. Annu Rev Cell Biol 4:405428. CrossRef Medline

Benovic JL, DeBlasi A, Stone WC, Caron MG, Lefkowitz RJ (1989) Betaadrenergic receptor kinase: primary structure delineates a multigene family. Science 246:235-240. CrossRef Medline

Benton R, Sachse S, Michnick SW, Vosshall LB (2006) Atypical membrane topology and heteromeric function of Drosophila odorant receptors in vivo. PLoS Biol 4:e20. CrossRef Medline

Benton R, Vannice KS, Vosshall LB (2007) An essential role for a CD36related receptor in pheromone detection in Drosophila. Nature 450:289293. CrossRef Medline

Benton R, Vannice KS, Gomez-Diaz C, Vosshall LB (2009) Variant ionotropic glutamate receptors as chemosensory receptors in Drosophila. Cell 136:149-162. CrossRef Medline

Blom N, Gammeltoft S, Brunak S (1999) Sequence and structure-based prediction of eukaryotic protein phosphorylation sites. J Mol Biol 294:13511362. CrossRef Medline

Cafaro J (2016) Multiple sites of adaptation lead to contrast encoding in the Drosophila olfactory system. Physiol Rep 4:e12762. CrossRef Medline

Cao LH, Jing BY, Yang D, Zeng X, Shen Y, Tu Y, Luo DG (2016) Distinct signaling of Drosophila chemoreceptors in olfactory sensory neurons. Proc Natl Acad Sci U S A 113:E902-E911. CrossRef Medline

Clyne PJ, Warr CG, Carlson JR (2000) Candidate taste receptors in Drosophila. Science 287:1830-1834. CrossRef Medline

Couto A, Alenius M, Dickson BJ (2005) Molecular, anatomical, and functional organization of the Drosophila olfactory system. Curr Biol 15:15351547. CrossRef Medline

Das S, Sadanandappa MK, Dervan A, Larkin A, Lee JA, Sudhakaran IP, Priya R, Heidari R, Holohan EE, Pimentel A, Gandhi A, Ito K, Sanyal S, Wang JW, Rodrigues V, Ramaswami M (2011) Plasticity of local GABAergic interneurons drives olfactory habituation. Proc Natl Acad Sci U S A 108: E646-E654. CrossRef Medline

Dweck HK, Ebrahim SA, Thoma M, Mohamed AA, Keesey IW, Trona F, Lavista-Llanos S, Svatoš A, Sachse S, Knaden M, Hansson BS (2015) Pheromones mediating copulation and attraction in Drosophila. Proc Natl Acad Sci U S A 112:E2829-E2835. CrossRef Medline

Getahun MN, Olsson SB, Lavista-Llanos S, Hansson BS, Wicher D (2013) Insect odorant response sensitivity is tuned by metabotropically autoregulated olfactory receptors. PLoS One 8:e58889. CrossRef Medline

Getahun MN, Thoma M, Lavista-Llanos S, Keesey I, Fandino RA, Knaden M, Wicher D, Olsson SB, Hansson BS (2016) Intracellular regulation of the insect chemoreceptor complex impacts odor localization in flying insects. J Exp Biol 219:3428-3438. CrossRef Medline

Ha TS, Smith DP (2006) A pheromone receptor mediates 11-cis-vaccenyl acetate-induced responses in Drosophila. J Neurosci 26:8727-8733. CrossRef Medline

Hallem EA, Carlson JR (2004) The odor coding system of Drosophila. Trends Genet 20:453-459. CrossRef Medline

Hallem EA, Carlson JR (2006) Coding of odors by a receptor repertoire. Cell 125:143-160. CrossRef Medline

Han C, Jan LY, Jan YN (2011) Enhancer-driven membrane markers for analysis of nonautonomous mechanisms reveal neuron-glia interactions in Drosophila. Proc Natl Acad Sci U S A 108:9673-9678. CrossRef Medline

Hausdorff WP, Lohse MJ, Bouvier M, Liggett SB, Caron MG, Lefkowitz RJ (1990) Two kinases mediate agonist-dependent phosphorylation and desensitization of the beta 2-adrenergic receptor. Symp Soc Exp Biol 44: 225-240. Medline

Inagaki HK, Jung Y, Hoopfer ED, Wong AM, Mishra N, Lin JY, Tsien RY, Anderson DJ (2014) Optogenetic control of Drosophila using a redshifted channelrhodopsin reveals experience-dependent influences on courtship. Nat Methods 11:325-332. CrossRef Medline
Jin X, Ha TS, Smith DP (2008) SNMP is a signaling component required for pheromone sensitivity in Drosophila. Proc Natl Acad Sci U S A 105: 10996-11001. CrossRef Medline

Jones WD, Cayirlioglu P, Kadow IG, Vosshall LB (2007) Two chemosensory receptors together mediate carbon dioxide detection in Drosophila. Nature 445:86-90. CrossRef Medline

Kurahashi T, Menini A (1997) Mechanism of odorant adaptation in the olfactory receptor cell. Nature 385:725-729. CrossRef Medline

Kurtovic A, Widmer A, Dickson BJ (2007) A single class of olfactory neurons mediates behavioural responses to a Drosophila sex pheromone. Nature 446:542-546. CrossRef Medline

Kwon JY, Dahanukar A, Weiss LA, Carlson JR (2007) The molecular basis of CO2 reception in Drosophila. Proc Natl Acad Sci U S A 104:3574-3578. CrossRef Medline

Larsson MC, Domingos AI, Jones WD, Chiappe ME, Amrein H, Vosshall LB (2004) Or83b encodes a broadly expressed odorant receptor essential for Drosophila olfaction. Neuron 43:703-714. CrossRef Medline

Lee AM, Wu DF, Dadgar J, Wang D, McMahon T, Messing RO (2015) PKCepsilon phosphorylates alpha4beta2 nicotinic ACh receptors and promotes recovery from desensitization. Br J Pharmacol 172:4430-4441. CrossRef Medline

Lin CC, Prokop-Prigge KA, Preti G, Potter CJ (2015) Food odors trigger Drosophila males to deposit a pheromone that guides aggregation and female oviposition decisions. eLife 4:e08688. Medline

Lin JY, Knutsen PM, Muller A, Kleinfeld D, Tsien RY (2013) ReaChR: a red-shifted variant of channelrhodopsin enables deep transcranial optogenetic excitation. Nat Neurosci 16:1499-1508. CrossRef Medline

Morgan DJ, Davis BJ, Kearn CS, Marcus D, Cook AJ, Wager-Miller J, Straiker A, Myoga MH, Karduck J, Leishman E, Sim-Selley LJ, Czyzyk TA, Bradshaw HB, Selley DE, Mackie K (2014) Mutation of putative GRK phosphorylation sites in the cannabinoid receptor 1 (CB1R) confers resistance to cannabinoid tolerance and hypersensitivity to cannabinoids in mice. J Neurosci 34:5152-5163. CrossRef Medline

Pitts S, Pelser E, Meeks J, Smith D (2016) Odorant responses and courtship behaviors influenced by at 4 neurons in Drosophila. PLoS One 11: e0162761. CrossRef Medline

Ronderos DS, Lin CC, Potter CJ, Smith DP (2014) Farnesol-detecting olfactory neurons in Drosophila. J Neurosci 34:3959-3968. CrossRef Medline

Sato K, Pellegrino M, Nakagawa T, Nakagawa T, Vosshall LB, Touhara K (2008) Insect olfactory receptors are heteromeric ligand-gated ion channels. Nature 452:1002-1006. CrossRef Medline

Spradling AC, Rubin GM (1982) Transposition of cloned P elements into Drosophila germline chromosomes. Science 218:341-347. CrossRef Medline

Stanczyk NM, Brookfield JF, Field LM, Logan JG (2013) Aedes aegypti mosquitoes exhibit decreased repellency by DEET following previous exposure. PLoS One 8:e54438. CrossRef Medline

Tachibana S, Touhara K, Ejima A (2015) Modification of male courtship motivation by olfactory habituation via the GABAA receptor in Drosophila melanogaster. PLoS One 10:e135186. CrossRef Medline

Vosshall LB, Amrein H, Morozov PS, Rzhetsky A, Axel R (1999) A spatial map of olfactory receptor expression in the Drosophila antenna. Cell 96: 725-736. CrossRef Medline

Vosshall LB, Wong AM, Axel R (2000) An olfactory sensory map in the fly brain. Cell 102:147-159. CrossRef Medline

Weiss S, Dascal N (2015) Molecular aspects of modulation of L-type calcium channels by protein kinase C. Curr Mol Pharmacol 8:43-53. CrossRef Medline

Weller M, Virmaux N, Mandel P (1975) Light-stimulated phosphorylation of rhodopsin in the retina: the presence of a protein kinase that is specific for photobleached rhodopsin. Proc Natl Acad Sci U S A 72:381-385. CrossRef Medline

Wicher D, Schäfer R, Bauernfeind R, Stensmyr MC, Heller R, Heinemann SH, Hansson BS (2008) Drosophila odorant receptors are both ligand-gated and cyclic-nucleotide-activated cation channels. Nature 452:1007-1011. CrossRef Medline 